\title{
LEALTAD CONSTITUCIONAL Y PARTIDOS POLÍTICOS ${ }^{1}$
}

\author{
LEONARDO ÁLVAREZ ÁLVAREZ \\ Profesor Asociado de Derecho Constitucional \\ Universidad de Oviedo
}

SUMARIO

1. Introducción

2. El concepto de lealtad constitucional

3. El principio de lealtad constitucional como instituto de defensa del Estado y no de defensa de la Constitución

4. El principio de lealtad constitucional en la Constitución española de 1978

5. La plasmación normativa del principio de lealtad constitucional frente a los partidos políticos en el art. $6 \mathrm{CE}$

6. La concreción del principio de lealtad constitucional en la LO 6/2002, de 27 de junio, de partidos políticos. La construcción tácita de un principio de defensa de la Constitución

7. El contenido del principio de lealtad constitucional frente a los partidos políticos

Quien pueda invocar el apoyo sobrenatural y la inspiración divina en su querer y actuación política puede tener derecho a cerrar su oído a la voz de los bombres e imponer su voluntad, como el bien de valor absoluto, también contra la mayoría y contra un conjunto de incrédulos que quieren algo diferente.

(Hans Kelsen, Staatsform und Weltanschauung, 1933)

1. El presente trabajo constituye una versión reelaborada y ampliada de la comunicación presentada en el I Congreso de la Asociación de Constitucionalistas de España celebrado en Toledo los días 21 y 22 de noviembre de 2002.

UNED. Teoria y Realidad Constitucional, núms. 10-11, 2. ${ }^{\circ}$ semestre 2002-1. ${ }^{\mathrm{er}}$ semestre 2003, pp. 445-468 


\section{INTRODUCCIÓN}

La LO 6/2002, de 27 de junio, de Partidos Políticos representa -en lo que a su finalidad se refiere- la legítima pretensión del ordenamiento español de defenderse frente a comportamientos que constituyan una infracción de sus normas. La cuestión capital reside en determinar qué clase de defensa es la que permite articular nuestro ordenamiento, en definitiva, frente a qué tipo de comportamientos ha de responder. La lealtad constitucional representa una determinada manera de plantear la defensa del ordenamiento jurídico sobre la base de un particular modo de concebir la infracción sus normas. La lealtad constitucional constituye el fundamento de ilicitud de comportamientos que supongan un menoscabo de la eficacia de las normas que expresan la identidad del ordenamiento. Esta vinculación entre lealtad y eficacia del ordenamiento jurídico se desvincula de la clásica concepción de la lealtad constitucional circunscrita a una adhesión a valores subyacentes al documento constitucional positivo, construida sobre la base de un concepto material de Constitución. En ese sentido, el concepto de lealtad constitucional se vincula a la idea de ordenamiento jurídico y no a la materialización del concepto de Constitución. Por ello, la lealtad constitucional constituye un instituto avalorativo.

La eficacia de las normas que expresan la identidad del ordenamiento español constituye precisamente la finalidad de la LO 6/2002, de 27 de junio, de Partidos Políticos, al prever la disolución de aquéllos que pongan en peligro el funcionamiento de los principios democráticos. La finalidad de este estudio consiste en analizar si esta lealtad constitucional frente a partidos políticos establecida en la LO 6/2002 resulta admitida por la CE de 1978. Como se pondrá de manifiesto, a pesar de que la eficacia de las normas que consagran la identidad del ordenamiento constituye una pretensión normativa de la CE, su desarrollo por parte de la LO 6/2002́, de 27 de junio, de Partidos Políticos, plantea capitales problemas de adecuación a la concepción constitucionalmente adecuada de la lealtad constitucional.

\section{EL CONCEPTO DE LEALTAD CONSTITUCIONAL}

\section{a) LA EFICACIA DE LAS NORMAS COMO CONDICIÓN DE VALIDEZ DEL ORDENAMIENTO JURÍDICO}

El ordenamiento jurídico se concibe, ante todo, como un orden social, esto es, como un complejo de normas que tienen por objeto regular las relaciones entre individuos. De tal modo, el ordenamiento jurídico desempeña una función equiparable al orden político o el moral que, de igual manera, regulan relaciones interindividuales. Sin embargo, el carácter distintivo de las normas que conforman el ordenamiento jurídico -y que permite diferenciar- 
las de las que integran otros órdenes sociales- reside en que la regulación de las relaciones entre individuos tiene lugar mediante la determinación de las condiciones de ejercicio de la fuerza física -órgano, procedimiento y supuesto de hecho- ${ }^{2}$. No obstante, esta regulación de las relaciones entre individuos sólo puede considerarse válida, y por tanto diferenciada de la realizada por los demás órdenes sociales, si posee un fundamento autónomo de validez ${ }^{3}$. Ello es lo que se expresa precisamente con el concepto de soberanía, cualidad que, predicada del ordenamiento jurídico, alude a que la validez de sus normas no deriva de ningún otro orden normativo superior a él ${ }^{4}$. Sin embargo, la soberanía no se presenta exclusivamente como una cuestión de validez. Para que se pueda hablar de un ordenamiento jurídico diferenciado de otros órdenes sociales, esto es, de un orden soberano, éste además de poseer su propio fundamento de validez debe ser, a grandes rasgos, eficaz. De tal modo, la eficacia de sus normas se presenta como condición de validez del ordenamiento jurídico en su conjunto 5 .

Con independencia de cuál sea este grado - en realidad, difícilmente cuantificable por su definición en términos de ser- parece claro que dicha eficacia general no se ve de igual manera amenazada por la ineficacia de las normas que ocupan un rango inferior en el ordenamiento que por la que afecte a su fundamento mismo de validez, esto es, a la Constitución. En realidad, un ordenamiento difícilmente puede ser eficaz si su fundamento de validez no resulta también eficaz ${ }^{6}$. Sin embargo, la eficacia de la norma fundamentante no puede medirse con arreglo a la eficacia de la totalidad de disposiciones que la conforman, sino principalmente a partir de la de sus normas fundamentales, aquellas que determinan su identidad ${ }^{7}$. La concepción de la Constitución como fundamento de validez de las normas del ordenamiento jurídico exige, en la determinación de su eficacia, tener en cuenta precisamente la eficacia de aquellas normas que organizan la creación normativa, en particular, las que inciden en la forma de Estado y en la forma de gobierno. En ese sentido, la eficacia de los principios estructurales se presenta como una cuestión fundamental para poder construir la eficacia como condición de validez del ordenamiento.

2. Sobre ello cfr. H. KELSEN, Reine Rechtslebre, ed. Franz Deuticke, Viena, 1976, pp. 25, 34 y ss., 60 .

3. Cfr. H. KELSEN, ibidem, pp. 200 y ss., J. Jellinek, Allgemeine Staatslebre, ed. Julius Springer, 3. edición, 5. a reimpresión, Berlín, 1929, pp. 321-323.

4. Véase H. KELSEN, Allgemeine Staatslehre, ed. Max Gehlen, Bad Homburg, Berlín, Zurich, 1966 , pp. 103 y 104. y 19.

5. Cfr. H. KELSEN, Reine Rechtslebre, op. cit., p. 219; Allgemeine Staatslebre, op. cit., pp. 18

6. Cfr. H. KelSEN, "Vom Geltungsgrund des Rechts" en H. Klekatsky, R. Marcic, H. Schambeck (edits.), Die Wiener Rechtstbeoretische Schule, ed. Europa, Viena, Francfort, Zúrich, 1968, p. 1422.

7. Es claro que la eficacia de la Constitución española de 1978 no puede enjuiciarse a partir de los arts. 4 y 5 en los que se establecen los colores de la bandera o la capitalidad del Estado, respectivamente. 
b) LA LEALTAD CONSTITUCIONAL COMO PLASMACIÓN NORMATIVA DE LA EFICACIA COMO CONDICIÓN DE VALIDEZ DEL ORDENAMIENTO JURÍDICO

Cuando la eficacia del ordenamiento jurídico deja de presentarse como condición fáctica para la presuposición de su validez y pasa a concebirse como una pretensión normativa de la norma constitucional, aquélla se convierte en el principio de lealtad constitucional. En ese sentido, el principio de lealtad constitucional encarna la pretensión normativa de la Constitución de dotar de eficacia a sus principios estructurales ${ }^{8}$. De tal modo, la lealtad constitucional se presenta como un principio interpretativo que debe tenerse en cuenta para determinar el contenido normativo de las normas positivas que conforman el ordenamiento jurídico'. El principio de lealtad niega amparo normativo a actividades que menoscaben o puedan menoscabar-según tal principio adquiera un contenido represivo o preventivo, la eficacia de las normas que determinan los principios estructurales ${ }^{10}$. Por ello, no cualquier infracción normativa -al margen de que ésta sea considerada como ilícita- constituye una vulneración del principio de lealtad constitucional, sino tan sólo aquella que adquiera una entidad tal como para lesionar la eficacia misma de los principios estructurales.

\section{EL PRINCIPIO DE LEALTAD CONSTITUCIONAL COMO INSTITUTO DE DEFENSA DEL ESTADO Y NO DE DEFENSA DE LA CONSTITUCIÓN}

El principio de lealtad constitucional puede concebirse como instituto de defensa de la Constitución o de defensa del Estado. En realidad, a tal distinción

8. Por ello se ha calificado a la lealtad constitucional como un instituto de carácter reflexivo, esto es, dispuesto por la Constitución para su propia defensa, cfr. E. DenNingER, "Der Schutz der Verfassung" en E. Benda, W. Maihofer, H.-J. Vogel (edits.), Handbuch des Verfassungsrechts, ed. De Gruyter, Berlín, Nueva York, 1983, p. 1294; N. Luhmann, Soziologische Aufklärung 5. Konstruktivistische Perspektiven, ed. Westdeutcher, Opladen, 1990, pp. 15 y 16.

9. El principio de lealtad constitucional es el que se encuentra implícito en la construcción doctrinal del principio de efectividad de los derechos fundamentales. En concreto, este principio es la causa de la denominada dimensión objetiva de los derechos fundamentales conforme a la cual estas normas se presentan, además de como una prohibición, como un mandato de optimización dirigido al poder público, cfr. C.-G. PESTALOzZA, "Kritische Bemerkungen zur Grundrechtsauslegung, Der Staat, núm. 4, 1963, p. 444.

10. Ello puede apreciarse, por ejemplo, en el principio alemán de la lealtad federal (Bundestreue). Merced al mismo, se declaran antijurídicos los comportamientos de los miembros del Estado federal que, aun ejerciendo competencias propias, menoscaben el funcionamiento del principio estructural del Estado federal, véase BVerfGE. 1, 299 (315), de 11 de mayo de 1952; 12, 205 (254), de 28 de febrero de 1961; 34, 9 (44), de 26 de julio de 1972; 39, 96 (108 y ss.), de 4 de marzo de 1975; 40, 96 (125), de 10 de junio de 1975; 41, 291 (308 y 310), de 10 de febrero de 1976; 61, 149 (205), de 19 de octubre de 1982; 81, 310 (337), de 22 de mayo de 1990). En la doctrina véase J. Isensee, "Idee und Gestalt des Föderalismus im Grundgesetz» en J. Isensee y P. Kirchhof (edits.), Handbuch des Staatsrechts, vol. IV, ed. CF. Müller, Heidelberg, 1990, p. 596. 
subyace la atribución de una diferente naturaleza jurídica al objeto del principio de lealtad constitucional ${ }^{11}$. Con el concepto defensa de la Constitución se alude a un principio interpretativo que sirve a la inmutabilidad frente al cambio de las materias sobre las que descansa el documento constitucional positivo ${ }^{12}$. De tal modo, el principio de defensa de la Constitución niega amparo normativo a actividades que, aun en observancia de las normas positivas, tengan como finalidad suprimir las materias subyacentes al texto constitucional ${ }^{13}$. La defensa de la Constitución implica, por tanto, declarar ilícitos los fines aun cuando los medios utilizados sean en sí correctos. Por ello, la defensa de la Constitución se dirige frente a enemigos y no simplemente infractores ${ }^{14}$. Como se puede apreciar, la defensa de la Constitución sólo adquiere sentido con arreglo a un concepto material de Constitución, esto es, allí donde se distingue entre normas positivas y determinadas materias que no resultan coincidentes en su naturaleza jurídica con aquéllas ${ }^{15}$. En puridad, defensa de la Constitución y lealtad constitucional no constituirían sino dos caras de una misma moneda. La defensa de la Constitución expresa, en realidad, una pretensión de eficacia permanente de las materias que subyacen al texto constitucional. El principio de defensa de la Constitución constituye, por tanto, un principio de lealtad constitucional que tiene por objeto materias que no tienen carácter jurídico-positivo y sobre las que, además -a consecuencia de su naturaleza suprapositiva-, pesa una garantía de intangibilidad $^{16}$. El objeto del principio de lealtad constitucional cambia radicalmente

11. Un aspecto que conducirá a conferir "fundamentalidad" -erigiéndose en objeto del principio de lealtad constitucional- a diferentes normas.

12. Véase C. SchmrT, Der Hüter der Verfassung, ed. Duncker \& Humblot, Berlín, 1985, p. 15.

13. Cfr. E. DenNingER, "Verfassungstreue und Verfassungsscbutz", VVDStRL, núm. 37, 1978, p. 18.

14. Véase I. DE OtTo Pardo, Defensa de la Constitución y partidos politicos, ed. Centro de Estudios Constitucionales, Madrid, 1985, p. 15.

15. Cfr. G. Röllecke, "Verfassungstreue und Schutz der Verfassung" en idem, Augeklärter Positismus Ausgewäblte Schriften zu den Voraussetungen des Verfassungsstaates, ed. CF. Müller, Heidelberg, 1995, p. 167.

16. El problema que presenta esta concepción del principio de lealtad constitucional como instituto de defensa de la Constitución deriva del concepto material de Constitución sobre el que aquel se construye, en concreto, del particular modo de atribuir la "fundamentalidad" a determinadas normas. Para la doctrina material, se atribuye el carácter de "fundamental" -por determinar la identidad de la Constitución- a ciertas normas suprapositivas al margen de si éstas tienen o no el carácter de principio estructural desde un punto de vista normológico. Así, por ejemplo, en la teoría integracionista de Constitución, los símbolos -además de los principios estructurales- forman parte de aquellas normas sobre las que el texto constitucional descansa, presentándose como objeto del principio de lealtad constitucional, cfr. R. Smend, "Verfassung und Verfassungsrecht" en idem, Staatsrechtlichen Abhandlungen, ed. Duncker \& Humblot, Berlín, 1968, pp. 217 y 218. En el contexto de la Ley. Fundamental de Bonn de 1949 se ha llegado a afirmar que la capitalidad del Estado alemán en Berlín constituye una decisión que pertenece a la subjetividad del pueblo y que ha permanecido subyacente incluso frente a la división de las dos Alemanias, cfr. R. Scholz, "Der Status Berlins" en J. Isensee y P. Kirchhof (edits.), Handbuch des Staatsrechts, vol. I, ed. CF. Müller, Heidelberg, 1987, p. 356. Sin embargo, esta precisión material del objeto de la lealtad constitucional conduce a resultados incompatibles con la finalidad de este concepto mismo, pues la pretensión de eficacia que expresa la lealtad constitucional sólo cobra sentido lógicamente res- 
donde éste se concibe como un instituto de defensa del Estado. El concepto defensa del Estado engloba un conjunto de normas y principios que tienen como finalidad la protección frente a la infracción de normas positivas ${ }^{17}$-al margen de si éstas se presentan como inmodificables o no-. El objeto del principio de lealtad constitucional se encuentra en tal caso conformado por normas jurídicas positivas. Si la Constitución se concibe como una norma de derecho positivo, las normas que conforman la identidad de la Constitución no pueden ser sino exclusivamente los principios estructurales. De este modo se excluye que puedan adquirir carácter de "fundamentales" normas jurídicas que no pueden presentarse en realidad como objeto de la lealtad constitucional, tal y como acontece en las teorías materiales de la Constitución. La atribución de la fundamentalidad a los principios estructurales resulta coherente con la eficacia de una organización inherente a la lealtad constitucional. Esa es precisamente la función de los principios estructurales: organizar y estructurar la creación normativa.

\section{EL PRINCIPIO DE LEALTAD CONSTITUCIONAL EN LA CONSTITUCIÓN ESPAÑOLA DE 1978}

\section{A) FUNDAMENTO DEL PRINCIPIO DE LEALTAD CONSTITUCIONAL}

El principio de lealtad constitucional en la CE aparece como exigencia dogmática de su concepción como norma jerárquicamente suprema. Tal supremacía se presenta como consecuencia de las notas de fuerza activa y fuerza pasiva que la norma constitucional de 1978 ha pretendido autoatribuirse frente a las demás normas del ordenamiento jurídico. La construcción del principio de lealtad constitucional como resultado de la supremacía constitucional se explica a partir de la indisponibilidad que la fuerza activa y pasiva confieren a las normas incluidas en el documento constitucional ${ }^{18}$. La pretensión de la Constitución de sustraer las normas incluidas en la forma constitucional a los poderes constituidos expresa su intención de conferirles eficacia. Allí donde falte la nota de la indisponibilidad del texto constitucional no cabe hablar de lealtad constitucional, toda vez que la eficacia de sus normas se halla condicionada a la voluntad del poder público ${ }^{19}$. Eso es lo que permite expli-

pecto a una determinada organización, cfr. P. Haberle, "Effizienz und Verfassung", AöR, núm. 98, 1973; J. Isensee, "Dienst nach Vorschrift als vorschriftswidriger Dienst", JZ, núm. 5, 1971, p. 75; W. Leisner, Effizienz als Rechtsprinzip, ed. JCB. Mohr, Tubinga, 1971, p. 8.

17. Cfr. D. Rauschning, Die Sicherung der Beachtung der Verfassungsrecht, ed. Gehlen, Berlín, 1969, p. 14.

18. Cfr. R. TномA, "Allgemeine Bedetung der Grundrechte" en H.- C. Nipperdey (edit.), Die Grundrechte und Grundpflichten der Reichsverfassung, ed. Keip, Francfort, 1975, pp. 8 y 9.

19. Eso es lo que aconteció en el contexto de la Constitución de Weimar de 1919 que permitió que fuese reformada por vía legislativa -art. 76-. En ese sentido, no puede hablarse de una norma jerárquicamente suprema, cfr. P. Badura, "Verfassungsänderung, Verfassungswandel, Ver- 
car que el principio de lealtad constitucional --como instituto jurídico-positivosólo haya podido construirse con posterioridad a la Segunda Guerra Mundial, cuando las Constituciones comienzan a erigirse en normas jerárquicamente supremas. De tal manera, el principio de lealtad en la $C E$ se deduce fundamentalmente de las normas en las que se expresan las notas de fuerza activa y fuerza pasiva, en particular en los arts. 9.1 -en este caso consagrada de manera general-, 161.1 y 166 y ss.

b) OBJETO DEL PRINCIPIO DE LEALTAD CONSTITUCIONAL: LA POSIBILIDAD DE REFORMA TOTAL DE LA CONSTITUCIÓN Y LA CONCEPCIÓN DEL PRINCIPIO DE LEALTAD COMO INSTITUTO DE DEFENSA DEL ESTADO

En la precisión del objeto del principio de lealtad constitucional desempeña un papel capital el art. $168 \mathrm{CE}$ en el que se admite que la misma pueda ser reformada en su totalidad. Ello se presenta como un argumento capital para negar que el principio de lealtad constitucional pueda concebirse como un instituto de defensa de la Constitución. La distinción entre normas positivas y determinadas materias que no resultan coincidentes en su naturaleza jurídica con ellas sólo puede resultar admisible allí donde se parte del carácter inmodificable de las materias que subyacen al documento constitucional ${ }^{20}$. De tal modo, la posibilidad de reforma total de la Constitución se presenta como el argumento fundamental para afirmar que la Constitución española ha pretendido concebirse a sí misma únicamente como norma de derecho positivo $^{21}$. En ese sentido, el objeto del principio de lealtad no puede sino determinarse en los preceptos que forman parte del documento constitucional, en particular, en aquellas que precisan los principios estructurales de Estado de derecho, Estado democrático, Estado social, el principio autonómico -art. 1.1- y la forma parlamentaria de gobierno -art. 1.3-. Todo ello conduce a que el principio de lealtad en la CE de 1978 se presente como un instituto de defensa del Estado y no de defensa de la Constitución ${ }^{22}$. Pero, además, precisamente porque tal normatividad positiva de la CE reconoce la posibilidad de reforma total, las normas del ordenamiento jurídico sólo pue-

fassungsgewobnibeitsrecbt" en J. Isensee y P. Kirchhof (edits.), Handbucb des Staatsrechts, vol. VII, ed. CF. Müller, Heidelberg, 1992, pp. 59 y 60. Esta indistinción entre el poder constituyente y poder legislativo impidió que pudiese ser construido correctamente un principio de lealtad constitucional.

20. Acerca de esta exigencia como inherente a las teorías materiales de Constitución véase B. Aláez Corral, Los límites materiales a la reforma de la Constitución española de 1978, ed. Centro de Estudios Políticos y Constitucionales, Madrid, 2000, pp. 61 y ss.

21. Otros datos que permiten avalar tal conclusión pueden ser las notas formales de la unidad documental y la rigidez y la pretensión de la Constitución de identificarse con las normas positivas que conforman su texto constitucional -arts. 161, 168-, cfr. B. Aláez Corral, ibidem, p. 268. y 36.

22. Cfr. I. DE OTTO PARDo, Defensa de la Constitución y partidos políticos, op. cit., pag. 35 
den presentarse como límites a la acción y no como límites a los fines por ella perseguidos. Con ello se niega también la posibilidad de que, en base a normas positivas, pueda llegarse a la consecuencia a la que conduce la defensa de la Constitución: la ilicitud de sus enemigos ${ }^{23}$. Precisamente porque cualquier ideología puede llegar a formar parte de la Constitución, en un ordenamiento democrático, los sometidos al mismo deben estar en condiciones de poder perseguirlas ${ }^{24}$.

\section{LA PLASMACIÓN NORMATIVA DEL PRINCIPIO DE LEALTAD CONSTITUCIONAL FRENTE A LOS PARTIDOS POLÍTICOS EN EL ART. 6 CE}

\section{a) EL ART. 6 CE COMO FUNDAMENTO DE LA DISTINCIÓN ENTRE EL PRINCIPIO DE LEALTAD CONSTITUCIONAL Y EL MANDATO DE RESPETO}

\section{A LA CONSTITUCIÓN Y A LA LEY}

$\mathrm{El}$ art. $6 \mathrm{CE}$ dispone respecto de los partidos políticos que su estructura interna y funcionamiento deberán ser democráticos. En lo que se refiere al necesario funcionamiento democrático, si lo que se pretendió fue que los partidos - de conformidad con el mandato general establecido en el art. 9.1 CE de sujeción al derecho positivo de ciudadanos y poderes públicos- no pudiesen infringir aquellas normas positivas en las que se consagra el principio democrático, aquella exigencia carece de todo sentido. Para ello hubiese bastado el mandato de respeto a la Constitución y a la ley prescrito en el mismo art. $6 \mathrm{CE}$. Un modo coherente de dotar de sentido a la exigencia de funcionamiento democrático de los partidos es concebirla como la plasmación normativa del principio de lealtad constitucional. En ese sentido, la cláusula "funcionamiento democrático" de los partidos políticos constituiría el presupuesto legitimador para negar amparo normativo a actividades de los mismos que -cumpliendo o aun incumpliendo las normas- menoscaben o puedan menoscabar

23. La intangibilidad de determinadas materias, presupuesto de la construcción material de la defensa de la Constitución, resulta también compatible con su carácter jurídico-positivo (un análisis de esta cuestión dogmática puede apreciarse en E. Wegge, Zur normative Bedeutung des Demokratieprinzips nach art. 79. 3 Abs. 3 GG. Ein verfassungsdogmatischer Beitrag zur Rationalität des Rechts, ed. Nomos Verlagsgesellsschaft, Baden-Baden, 1996, pp. 27 y ss.). Sin embargo, la ilicitud de los enemigos de tales materias no puede considerarse, en puridad, como expresión de un principio de defensa de la Constitución ya que el carácter distintivo de éste es la naturaleza juridico-positiva de su objeto. El principio de lealtad respecto de normas jurídico-positivas en las que en todas o alguna concurre la nota de la intangibilidad debe considerarse como un instituto de defensa del Estado.

24. Cfr. I. DE OTTO PARDo, Defensa de la Constitución y partidos politicos, op.cit., p. 27; M. Aragón Reyes, Constitución y democracia, ed. Tecnos, Madrid, 1989, pp. 49 y 50; F.J. Díaz-Revorio, La Constitución como orden abierto, ed. Mc-Graw-Hill, Madrid, 1997, p. 22. 
la eficacia del principio democrático. De tal manera no cualquier infracción de las normas reguladoras del principio democrático supone una vulneración de la cláusula funcionamiento democrático de los partidos, aunque lo sea del mandato de respeto a la Constitución y a la ley, sino tan sólo aquella que pueda lesionar el funcionamiento mismo del principio democrático. Además, la expresa alusión al instituto de la sujeción de los partidos al derecho positivo en el art. $6 \mathrm{CE}$ cobra sentido, sin caer en la reiteración de lo dicho en el art. 9.1 CE, por oposición al particular modo de sujeción que se deduce del mandato de funcionamiento democrático de los partidos. En definitiva, el art. $6 \mathrm{CE}$ articula dos diferentes supuestos de ilicitud de los partidos políticos, el primero, basado en la infracción de la Constitución y la ley -sujeción al derecho positivo-y, el segundo, en el menoscabo del principio democrático -lealtad constitucional-. Sin embargo, estos dos supuestos de ilicitud no funcionan antitéticamente. Algunos supuestos de infracción de la Constitución y la ley pueden representar, al mismo tiempo, una vulneración de la lealtad constitucional. Ello acontece cuando la infracción de la Constituciôn y de la ley posee una entidad tal como para menoscabar la eficacia misma del principio democrático. Sólo cuando se encuentre ausente esta entidad se admite la infracción del mandato de sujeción a la Constitución y a la ley y no del principio de lealtad constitucional.

Una vez precisado esto, resulta necesario resaltar que el art. $6 \mathrm{CE}$ sólo ha erigido en objeto de la lealtad constitucional de los partidos políticos el principio democrático y no el resto de principios estructurales de la CE. Un principio democrático, cuya configuración constitucional, como consecuencia de la posibilidad de reforma total de la Constitución, se ha de concebir desde un punto de vista procedimental tal y como ha puesto de relieve la STC 122/1983, de 16 de diciembre,

La fidelidad a la Constitución ... puede(n) entenderse como el compromiso de aceptar las reglas de juego político y el orden juridico existente en tanto existe y a no intentar su transformación por medios ilegales. La fidelidad, en esta linea interpretativa, no entraña una probibición de representar $y$ de perseguir ideales políticos diversos de los encarnados en la Constitución ..., siempre que se respeten aquellas reglas de juego. (FJ 7. ${ }^{\circ}$.

Es por ello que, en base al principio de lealtad constitucional, sólo puede declararse la ilicitud de los partidos políticos por la adopción de medios antidemocráticos y no por los fines por ellos perseguidos 25 , pues esto último sería consustancial a una democracia valorativa y no procedimental26.

25. Cfr. I. DE OTTO PARDO, Defensa de la Constitución y partidos políticos, op. cit., p. 27 ; R. L. Blanco Valdés, Los partidos políticos, ed. Tecnos, Madrid, 1990, pp. 135 y ss.

26. Véase J. BECKer, "Die Webrhafte Demokratie des Grundgesetzes" en J. Isensee y P. Kirchhof (edits.), Handbuch des Staatsrechts, vol. VII, op. cit., p. 312. 


\section{b) LA ILICITUD PENAL DE LOS PARTIDOS COMO RESPUESTA A LA INFRACCIÓN DEL MANDATO DE RĖSPETO A LA CONSTITUCIÓN Y A LA LEY}

La concreción normativa del mandato de respeto a la Constitución y a la ley de los partidos políticos se halla en la legislación penal a la que remite el art. 22.2 CE en el que se consagra uno de los límites al ejercicio del derecho de asociación, del que los partidos son consecuencia ${ }^{27}$. El art. 22.2 dispone que las asociaciones que persigan fines o utilicen medios tipificados como delito son ilegales. El legislador penal ha reputado, en primer lugar, asociaciones penalmente ilícitas de las que tengan por objeto cometer algún delito o, después de constituidas, promuevan su comisión -art. 515.1. - . Si bien perseguir fines delictivos -art. 22.2 CE-y tener por objeto cometer algún delito -art. 515. $1 .^{\circ} \mathrm{CP}-$ no son expresiones formalmente equivalentes, materialmente ambas dicciones parecen resultar coincidentes. Fin delictivo y objetivo delictivo no pueden sino referirse a un mismo supuesto ${ }^{28}$. En ese sentido, en base al art. 515. $1 .^{\circ}$, se desplaza la concreción normativa de la cláusula "tener por objeto cometer algún delito" -o si se quiere, perseguir fines delictivos (art. 22.2 CE) al resto de disposiciones del CP, a las que el art. 515.1 remite de un modo tácito. De acuerdo con ello, deben considerarse asociaciones penalmente ilícitas, por ejemplo, las que tengan por objeto la comisión de homicidios ${ }^{29}$ o la apología de la violencia contra personas, grupos o asociaciones por su ideología, religión o creencias, entre otras circunstancias, contempladas como actividades delictivas en los arts. 138 y $510.1 \mathrm{CP}$, respectivamente. En lo que aquí interesa, la ilicitud penal prescrita en el art. 515.1. ${ }^{\circ}$-en desarrollo del art. $22.2-$ concibe como ilícitos los partidos que adopten actividades contrarias a las normas constitucionales, como por ejemplo, al art. $15 \mathrm{CE}$-derecho a la vida e integridad física-30. Esta misma infracción de normas constitucionales también se sanciona penalmente en los arts. $515.2 .^{\circ}, 3 .^{\circ}$ y $4 .^{\circ}$, en los que se conciben

27. En la jurisprudencia véase la STC 3/1981, de 2 de febrero, FJ $1 .^{\circ}$. En la doctrina F. J. Bastida Freijedo, "La relevancia constitucional de los partidos politicos y sus diferentes significados. La falsa cuestión de la naturaleza jurídica de los partidos" en J. J. González Encinar (coord.), Derecho de partidos, ed. Espasa Calpe, Madrid, 1992, Pp. 82 y ss.; M. A. Presno Linera, Los partidos y las distorsiones juridicas de la democracia, ed. Ariel, Barcelona, 2000, pp. 42 y 43.

28. Una postura crítica respecto a esta posibilidad resulta adoptada por de Otto, para el que, sobre el análisis de la regulación penal realizada en el antiguo Código Penal de 1973, en el que el tipo penal ahora analizado era objeto de idéntica redacción, niega que tener por objeto cometer algún delito y perseguir fines delictivos puedan referirse a una misma cuestión, cfr. Defensa de la Constitución y partidos políticos, op. cit., p. 66. La tesis favorable a la equiparación entre la ilicitud constitucional del art. $22.2 \mathrm{CE}$ e ilicitud penal del art. $515.1 .^{\circ} \mathrm{CP}$ encuentra un amplio apoyo en la doctrina penalista, cfr. F. MuÑoz Conde, Derecho Penal. Parte especial, ed. Tirant lo Blanch, Valencia, 1999, pp. 788 y 789; M. Cobo del Rosal y J. Boix Reig, Comentarios a la legislación penal, ed. Edersa, Madrid, 1982, p. 138.

29. Si bien en este caso la asociación entraría posiblemente en el supuesto de asociación terrorista contemplado en el art. $515.2 .^{\circ} \mathrm{CP}$.

30. No hay que excluir la posibilidad de que la legislación penal pueda tutelar otros bienes de naturaleza infraconstitucional. 
como ilícitas las asociaciones que adopten medios violentos - art. $515.3 .^{\circ}-\mathrm{o}$ las que puedan llegar a emplearlos -las bandas armadas, organizaciones y grupos terroristas (art. 515.2..$^{\circ}$ y las asociaciones de carácter paramilitar (art. 515.4..$^{\circ}$-. Por el contrario, el derecho al honor del art. $18 \mathrm{CE}$-además del art. $15 \mathrm{CE}$ - es el que parece protegerse en el art. $515.5 .^{\circ}$ en el que se conciben como asociaciones ilícitas las que promuevan la violencia o el odio -en este último caso se tutelan de igual modo los arts. 14 y $16 \mathrm{CE}$ - contra personas, grupos o asociaciones por su ideología, religión o creencias entre otros casos. En virtud de todo ello, los supuestos de ilicitud establecidos en la legislación penal, a los que remite el art. $22.2 \mathrm{CE}$, son la respuesta a la infracción de las normas constitucionales en las que se regula el principio demócrático, en definitiva, del instituto de la sujeción. Sin embargo, el condicionamiento de la ilegalidad de las asociaciones por la $\mathrm{CE}$ a los supuestos de ilicitud penal no significa delegar en el legislador la posibilidad de articular un principio de lealtad respecto de las asociaciones, dada la ausencia de una cláusula en el art. $22 \mathrm{CE}$ como la relativa al funcionamiento democrático de los partidos del art. $6 \mathrm{CE}$. Pero es que además en el art. 22 ni siquiera se establece frente a las asociaciones el mandato de respeto a la Constitución y a la ley impuesto en el art. 6 respecto de los partidos. Como ha quedado dicho anteriormente, esta cláusula utilizada en el art. $6 \mathrm{CE}$, reiteración del mandato de sujeción del art. 9.1, sólo puede explicarse en su pretensión de distinguir entre lealtad y sujeción. Su ausencia en el art. 22 no implica lógicamente que las asociaciones no se encuentren sujetas al derecho positivo, consecuencia inherente al carácter normativo de la CE, sino a la ausencia respecto de ellas de un principio de lealtad constitucional ${ }^{31}$. Ello sólo resulta posible -además de frente a los partidos- frente a los sindicatos de trabajadores, asociaciones empresariales y los colegios profesionales a los que la $\mathrm{CE}$ exige en los arts. 7 y $36 \mathrm{CE}$ respectivamente, también un funcionamiento democrático.

31. De tal modo se excluye en España una regulación como la contenida en la Ley de Asociaciones alemana de 1964 , en cuyo art. 3.1 se dispone la ilicitud de las asociaciones cuyos fines y actividades sean contrarias a la legislación penal o sean contrarias al orden constitucional (BGBl. I, S. 593, BGBl III S. 2180-1). Esto resulta posible por la presencia de un principio de lealtad constitucional frente las asociaciones en el art. 9.2 de la Ley Fundamental de Bonn cuya dicción es idéntica a la expresada en esta Ley. La ausencia en la CE de un presupuesto legitimador en el art. 22 como el art. 9.2, impide que en la LO 1/2002, de 22 de marzo, reguladora del derecho de asociación, pueda caber lícitamente un supuesto de ilicitud parecido al consagrado en la regulación legal alemana. Frente a las asociaciones sólo puede afirmarse el mandato de respeto al ordenamiento jurídico -de forma similar al mandato de respeto a la Constitución y a la ley del art. $6 \mathrm{CE}-$ como el que se dispone en el art. 2.4 de la LO 1/2002 que dispone que la constitución de asociaciones y el establecimiento de su organización y funcionamiento se llevarán a cabo dentro del marco de la Constitución, de la presente Ley Orgánica y del resto del ordenamiento juridico. Es por ello que sobre el art. 2.5 de esta Ley en el que se establece que la organización interna y el funcionamiento de las asociaciones deben ser democráticos, con pleno respeto al pluralismo recaiga una duda razonable de inconstitucionalidad. 
C) Los supuestos De Ilicitud de LA LO 6/2002, DE 27 DE JUNiO, de PARTidos Políticos COMO ResPuesta a la vUlNeración Del PRINCIPIO DE LEALTAD CONSTITUCIONAL.

Si el CP -por remisión del art. 22.2 CE-, en concreto, el art. 515, representa la sanción frente a la infracción del mandato de respeto a la Constitución y a la ley dispuesto frente a los partidos en el art. $6 \mathrm{CE}$-por la infracción de las normas en las que se consagra el principio democrático-, la LO 6/2002, de 27 de junio, de Partidos Políticos -en adelante LPP-constituye la respuesta respecto de la vulneración del principio de lealtad constitucional. En su art.9.2 se dispone que un partido será declarado ilegal cuando su actividad vilnere los principios democráticos, particularmente cuando con la misma persiga deteriorar o destruir el régimen de libertades o imposibilitar o eliminar el sistema democrático, mediante alguna de las siguientes conductas, realizadas de forma reiterada y grave. En ese sentido, la ilicitud dispuesta por la LPP no tiene lugar sin más cuando se adopten las conductas previstas en los apartados a, b y c del art. 9.2 -muchas de ellas reconducibles a los supuestos de ilicitud penal del art. 515- sino cuando las mismas sean realizadas, como dispone la LPP, de forma reiterada y grave. De tal modo, no cualquier infracción de normas constitucionales se ubica dentro del supuesto de ilicitud de la LPP sino tan sólo aquélla que pueda menoscabar el funcionamiento mismo del principio democrático ${ }^{32}$. Por ello, la LPP no supone la respuesta frente a la inobservancia del mandato de respeto a la Constitución y a la ley del art. $6 \mathrm{CE}$, sino a la vulneración de la lealtad constitucional al principio democrático.

\section{LA CONCRECIÓN DEL PRINCIPIO DE LEALTAD CONSTITUCIONAL EN LA LO 6/2002, DE 27 DE JUNIO, DE PARTIDOS POLÍTICOS. LA CONSTRUCCIÓN TÁCITA DE UN PRINCIPIO DE DEFENSA DE LA CONSTITUCIÓN.}

Una vez determinada la concepción del principio de lealtad adecuada a la $\mathrm{CE}$, el análisis debe centrarse en este punto en analizar si la precisión de

32. Así, por ejemplo, en la Proposición de Ley Orgánica para la garantía de la democracia en los Ayuntamientos y la Seguridad de los Concejales presentada por los Grupos Parlamentarios Popular y Socialistá en el Congreso (BOCG. B Núm. 280.1) se propone la reforma del art. 2.2 de la LO 3/1987 de financiación de los Partidos Políticos. La nueva redacción propone que no puedan entregarse recursos procedentes de la financiación pública, cualquiera que sea su tipo y naturaleza, a favor de las formaciones politicas cuando, concurriendo las conductas previstas en el art. 9 de la Ley Orgánica de Partidos Políticos, no proceda por el grado de reiteración o gravedad de las mismas acordar su disolución. En ese sentido, la medida propuesta no responde a la infracción del principio de lealtad constitucional del art. $6 \mathrm{CE}$, ya que, como se dispone en el proyecto, no es necesario el menoscabo del principio democrático -al no requerirse la gravedad-, sino la infracción de alguna de sus normas en el modo establecido en el art. 9 LPP. 
los supuestos de hecho de vulneración del principio de lealtad realizada por la LPP es conciliable con la configuración constitucional de tal principio. La LPP surge inicialmente con la finalidad de erigir al principio democrático -conforme a la concepción procedimental que adquiere el mismo en la Constitución- en límite a las actividades de los partidos políticos y no a las finalidades políticas perseguidas por estos. Ello se deja claro en su Preámbulo en el que se establece que

\begin{abstract}
resulta necesario identificar y diferenciar con toda nitidez aquellas organizaciones que defienden y promueven sus ideas y programas, cualesquiera que estas sean, incluso aquellas que pretendan revisar el propio marco institucional, con un respeto escrupuloso de los métodos y principios democráticos, de aquellas otras que sustentan su acción política en la connivencia con la violencia, el terror, la discriminación, la exclusión y la violación de los derechos $y$ de las libertades ${ }^{33}$.
\end{abstract}

En ese sentido, se pretende compatibilizar, conforme a la consecuencia que acaba admitiendo la doctrina del $\mathrm{TC}^{34}$, la posibilidad constitucional de supresión de la democracia con la necesidad igualmente constitucional de que tal cosa deba realizarse de conformidad con los procedimientos democráticos. A pesar de ello, los supuestos de ilicitud de los partidos se articulan a partir de la nada afortunada dicción del art. 9.1 LPP de que sus actividades deberán respetar. . los valores constitucionales, expresados en los principios democráticos, $y$ en los derechos bumanos. El art. 9.1 presenta una gran similitud con los enunciados propios de una democracia militante vinculada a valores que declara ilícitas aquellas actividades que, aun respetuosas con la legalidad positiva, pretendan subvertir los valores subyacentes al documento constitucional ${ }^{35}$. El art. 9.1 LPP suscita una problemática similar a la del art. 4 de la Constitución francesa de 1958 en el que se impone a los partidos un mandato de respeto a los principios de la soberanía nacional y la democracia ${ }^{36}$. Sin embargo, la concre-

33. La negrita es nuestra.

34. Véase el epígrafe 4 a).

35. Este mandato de respeto a los principios democráticos es la norma que se deduce del enunciado normativo del art. 21.2 de la Ley Fundamental de Bonn en el que se dispone que los partidos politicos que por sus fines o por la actividad de sus militantes tengan como finalidad menoscabar o suprimir el orden democrático liberal [...], son inconstitucionales. Ello lo ha puesto de manifiesto, un modo más evidente, el Tribunal Constitucional Federal alemán al afirmar que como la pluralidad de ideologias y de intereses puede hacer prácticamente imposible la construcción de una voluntad estatal unitaria, debe entonces exigirse respecto de aquellos llamados a la construcción de la voluntad del Estado al menos un consenso en la afirmación de los valores fundamentales de la Constitución (BV̈erfGE. 5, 85 (134), de 17 de agosto de 1956). En la doctrina pueden consultarse los trabajos de J. Lameyer, Streitbare Demokratie. Eine Verfassungshermeneutische Untersuchung, ed. Duncker \& Humblot, Berlín, 1978, pp. 28 y ss.; y de E. Denninger, "Verfassungstreue und Schutz der Verfassung", op. cit., p. 17.

36. Sobre la base del ambiguo enunciado del art. $4 \mathrm{CF}$, la doctrina francesa ha debatido acerca de la posibilidad de construir un principio de lealtad constitucional como instituto de defensa de la Constitución o de defensa del Estado, sobre ello véase con carácter general P. Esplu- 
ción normativa del mandato de respeto a valores constitucionales en el art. 9.2 LPP permite soslayar, al menos en un principio, la exigencia de una lealtad constitucional a la democracia militante. En dicha disposición se establece que

un partido político será declarado ilegal cuando su actividad vulnere los principios democráticos particularmente cuando con la misma persiga deteriorar o destruir el régimen de libertades o imposibilitar o eliminar el sistema democrático mediante alguna de las siguientes conductas realizadas de forma reiterada y grave... ${ }^{37}$.

En ese sentido, la ilegalidad de los partidos políticos no tiene lugar cuando se persiga deteriorar o destruir el principio democrático -aspecto éste que conduciría a un principio de lealtad como defensa de la Constitución-, sino a su deterioro o destrucción a través de determinadas conductas que son las que se declaran ilícitas. La ilicitud no pesa sobre los fines partidistas sino sobre el particular modo en que ellos resultan perseguidos. Para que el art. 9 LPP pudiese ser considerado como un instituto de defensa de la Constitución, el deterioro o destrucción del principio democrático debieran reputarse ilícitos en cualquier caso con independencia de las conductas adoptadas para tal fin ${ }^{38}$, cosa que no realiza el art. 9.2 LPP. Las conductas que, conforme a los apartados a, b y c del art. 9.2 LPP, conducen a la ilicitud de los partidos políticos por su pretensión de deteriorar o destruir el principio democrático se analizarán a continuación.

9.2a) Vulnerar sistemáticamente las libertades y derechos fundamentales, promoviendo, justificando o exculpando los atentados contra la vida o la integridad de las personas, o la exclusión o persecución de personas por razón de su ideología, religión o creencias, nacionalidad, raza, sexo u orientación sexual.

El presente supuesto de ilicitud realiza una ponderación -de manera sólo similar al tipo penal de apología de la violencia-39. entre el derecho fundamen-

gas, "L'interdiction des partis politiques", Revue Française de Droit Constitutionnel, núm. 36, 1999, pp. 684 y ss. La mayoritaria negación de un principio de defensa de la Constitución se ha construido sobre la base de la concepción liberal de los derechos reconocidos en la Declaración de los Derechos del Hombre y del Ciudadano de 1789 a la que se remite la Constitución francesa, véase G. Burdeau, F. Hamon y M. Troper, Droit Constitutionnel, 25. edición, ed. Librairie Générale de Droit et Jurisprudence, París, 1997, p. 295; J. Giquel, Droit Constitutionnel et instituciones politiques, 15. a edición, ed. Montchrestien, París, 1997, pp. 81 y ss.. Por ello frente a los partidos políticos en el ordenamiento francés sólo cabe la lealtad constitucional como una forma de defensa del Estado.

37. La negrita es nuestra.

38. Cfr. I. DE OTTO PARDO, Defensa de la Constitución y partidos politicos, op. cit., p. 15.

39. El Código Penal entiende por apología la exposición, ante una concurrencia de personas o por cualquier medio de difusión, de ideas o doctrinas que ensalcen el crimen o enaltezcan a su autor. La apología sólo será delictiva como forma de provocación y si por su naturaleza y circunstancias constituye una incitación directa a cometer un delito (art. 18). Sin embargo, el art. 9.2 a) amplía las conductas consideradas apología en el CP. Parece claro que la promoción, jus- 
tal a la libertad de expresión del art. 20.1. ${ }^{\circ} \mathrm{CE}$ y determinados derechos, como el derecho a igualdad, el derecho a la vida e integridad física o a la libertad ideológica consagrados en los arts. 14, 15 y $16 \mathrm{CE}$ respectivamente-atentados contra la vida o la integridad de las personas así como la persecución de personas-. En lo que aquí interesa, la primera parte del art. 9.2 a) -promover, justificar o exculpar atentados contra la vida o la integridad de las personas- presenta al derecho del art. $15 \mathrm{CE}$ como un límite a la acción y no a los fines perseguidos mediante ella. Lo que el art. 9.2 a) LPP impide es que los fines partidistas sean difundidos lesionando el derecho a la vida e integridad física, resultando por tanto conciliable con el principio de lealtad constitucional como instituto de defensa del Estado. Mayores problemas suscita, no obstante, la segunda parte del art. 9.2 a), la relativa a promover, justificar o exculpar la exclusión de las personas por razón de su ideología, religión o creencias, nacionalidad, raza, sexo y orientación sexual. Ello constituye un supuesto de ilicitud similar al consagrado en el tipo penal del art. $515.5^{\circ}$ en el que declaran penalmente ilicitas las asociaciones -y por tanto, los partidos- que promuevan la discriminación o el odio... contra las personas, grupos o asociaciones por razón de su ideología, religión o creencias, la pertenencia de sus miembros o de alguno de ellos a una etnia, raza o nación, su sexo, orientación sexual, situación familiar, enfermedad o minusvalia. Parece claro que en el supuesto de ilicitud "exclusión de personas" del art. 9.2 a) -tal y como acontece con la cláusula "Odio contra las personas" del art. 515.5. - hallan cabida expresiones contrarias al derecho al honor del art. $18.1 \mathrm{CE}^{40}$. En ese sentido, el art. 9.2 a) LPP -como también el art. 515.5. - excluye que los fines de los partidos puedan ser perseguidos a través de actividades que supongan un desmerecimiento de la consideración ajena -honor en sentido objetivo- o la propia estimación personal

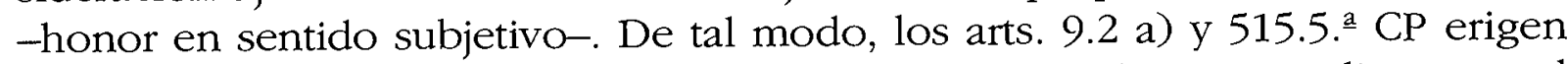
al art. 18.1 CE en límite al modo en que el discurso político se realiza y no al discurso mismo ${ }^{41}$. Sin embargo, en el supuesto de ilicitud del art. 9.2 a) pue-

tificación o exculpación de atentados contra la vida o la integridad de las personas del art. 9.2 a) LPP no suponen necesariamente una incitación directa a la comisión de un delito. Sólo si los supuestos de ilicitud de la LPP abarcan un mayor número de conductas que las englobadas en el delito de apología cobra sentido un supuesto de ilicitud como el del art. 9.2 LPP. De otro modo, la LPP remitiría al CP, como lo hace, por ejemplo, en el art. 10.2 a) al determinar la disolución de los partidos que incurran en los supuestos de asociación penalmente ilícita del art. $515 \mathrm{CP}$.

40. Cfr. M. L. CUERDA ARNAU, "El denominado delito de apología del genocidio. Consideraciones constitucionales", Poder Judicial, núm. 56, 1999, pp. 65 y ss, 99 y ss.

41. Esta concepción del derecho al honor del art. 18.1 como límite al derecho a la libertad de expresión del art. 20.1. ${ }^{\text {) }}$ ) queda patente en la STC 176/1995, de 11 de diciembre. En la misma se enjuicia la exaltación del nacionalsocialismo realizada mediante un cómic en el que se ridiculiza al pueblo judio. Como aprecia el TC, en el cómic se relatan una serie de episodios, cuyos escenarios son los campos de concentración nazis, o campos de exterminio, con alemanes de las Schutz-Staffel (SS) y judios como protagonistas y antagonistas de "conductas l...J inhumanas, viles y abyectas, con un claro predominio de aberraciones sexuales". "El transporte de prisioneros como si fuera ganado, la burla y el engaño del reparto de jabón antes de entrar en la cámara, el olor del gas y de los cadáveres, el aprovechamiento de restos humanos", con otros muchos episodios se 
den llegar a incluirse otro tipo de actividades cuya adecuación a la concepción procedimental del principio democrático resulta más dudosa. La concepción de la cláusula "exclusión de personas" en la LPP - como la relativa a la "discriminación y odio" en la legislación penal- no sólo permite englobar en ella actividades lesivas del derecho al honor. La "exclusión de personas" se entiende en la LPP en el sentido de aislamiento social, confrontación civil o cultura de enfrentamiento, como se deduce de la concreción de otras conductas genéricas en el art. 9.3 b). Esta amplitud del concepto exclusión puede llegar a permitir que, en el supuesto de ilicitud del art. 9.2 a), hallen cabida no sólo actividades, en sentido estricto, contrarias al derecho al honor sino doctrinas políticas construidas a partir de la desigualdad del ser humano y la consiguiente pretensión de exclusión y aislamiento de determinados grupos sociales, como el nazismo que, paradójicamente, puede llegar a formar parte del contenido constitucional. De tal manera, aquella disposición viene a erigir el derecho a la igualdad y la libertad ideológica de los arts. 14 y $16 \mathrm{CE}$ en límite al contenido del discurso. La ponderación realizada por el art. 9.2 a) entre los derechos fundamentales de los arts. 20.1 a) y los arts. 14 y $16 \mathrm{CE}$ acaba convirtiendo a la lealtad constitucional en instituto de defensa de la Constitución, contraviniendo la concepción constitucional de la democracia y del principio de lealtad.

Con todo, esta ponderación ha resultado compartida por el TC en el caso Violeta Friedmann (STC 214/1991, de 11 de noviembre) en el que se enjuician expresiones de un ex dirigente nacionalsocialista en las cuales, además de negar el holocausto, realiza juicios ofensivos en contra del pueblo judío. El TC plantea inicialmente el caso como una colisión entre el derecho fundamental a la libertad de expresión del art. 20.1 - como proyección de la libertad ideológica del art. 16- y el derecho al honor del art. 18.1 (FJ. 1. ${ }^{\circ}$ ). Sin embargo, la negación de la tutela de las expresiones en el art. 20.1 no se articula sobre la base de la concepción del derecho al honor como límite a la forma en que se realiza el discurso nacionalsocialista. La ilicitud de las expresiones se acaba desviando más bien a la desigualdad de la raza humana de la que parte el nacionalsocialismo, doctrina política que pretenden ensalzar las expresiones enjuiciadas. Como ha afirmado el TC,

así pues de la conjunción de ambos valores constitucionales, dignidad e igualdad de todas las personas, se bace obligado afirmar que ni el ejercicio de la libertad ideológica ni la de expresión pueden amparar manifestaciones

narran en tono de mofa, sazonando todo con expresiones insultantes o despectivas ("animales" o "carroña", entre otras). Sobre la base de esta apreciación, el TC afirma que el cómic convierte una tragedia bistórica en una farsa burlesca l... J por buscar deliberadamente y sin escrüpulo alguno el vilipendio del pueblo judio, con menosprecio de sus cualidades para conseguir asi el desmerecimiento en la consideración ajena [...J. Para negar el amparo de tales conductas en el derecho del art. 20.1, el TC afirma que la apología de los verdugos, glorificando su imagen $y$ justificando sus bechos, a costa de la bumillación de sus víctimas no cabe en la libertad de expresión como valor fundamental del sistema democrático que proclama nuestra Constitución (FJ. ${ }^{\circ} 5$ ). 
o expresiones destinadas a menospreciar o a generar sentimientos de bostilidad contra determinados grupos étnicos, de extranjeros o inmigrantes, religiosos o sociales, pues en un Estado como el español, social, democrático y de Derecho, los integrantes de aquellas colectividades tienen el derecho a convivir pacíficamente y a ser plenamente respetados por los demás miembros de la comunidad social. (FJ $8^{\circ}$ ).

En definitiva, el art. 9.2 a) LPP, aunque con carácter general pretende renunciar a declarar la ilicitud de fines políticos, emplea uno de los métodos para construir de forma subrepticia un mecanismo de defensa de la Constitución: la deliberada amplitud del supuesto de ilicitud formulado que permite que, junto a actividades ilícitas, puedan llegar a incluirse otras que manifiestan ideologías contrarias a la Constitución ${ }^{42}$. Por ello, el mejor remedio para evitar esta implícita construcción de un principio de defensa de la Constitución -exigido por otra parte por la concepción procedimental del principio democrático y por la consagración del pluralismo político como uno de los valores superiores del ordenamiento- es tipificar como ilícitas sólo actividades que supongan una lesión evidente y directa de otros derechos fundamentales.

9.2 b) Fomentar, propiciar.o legitimar la violencia como método para la consecución de objetivos políticos o para hacer desaparecer las condiciones precisas para el ejercicio de la democracia, del pluralismo y las libertades politicas.

En el art. 9.2 b) LPP se realiza una ponderación análoga a la practicada en el art. 9.2 a). En este caso, entre determinados derechos fundamentales como la libertad de expresión o el derecho de asociación de los arts. 20.1 a) y $22 \mathrm{CE}^{43}$, entre otros, y el derecho a la integridad física del art. $15 \mathrm{CE}$. Apa-

42. La articulación del pluralismo político como límite a lás finalidades perseguidas se percibe también en la STC 136/1999, de 20 de julio, sobre la Mesa Nacional de Herri Batasuna. En este caso, la argumentación realizada por el TC toma como punto de partida el instituto de la opinión pública libre que, en la jurisprudencia constitucional, tiene como finalidad favorecer la proyección de pensamientos, ideas y opiniones en el proceso de formación de la voluntad estatal al margen del contenido de aquéllas (STC 12/1982, de 31 de marzo). Sin embargo, en el caso, el instituto opinión pública libre se acaba convirtiendo precisamente en un límite al contenido del discurso, véase B. Aláez Corral, "Defensa de la Constitución, libertades de expresión e información y principio de proporcionalidad (A propósito de la STC. 136/1999, de 20 de julio), Repertorio Aranzadi del Tribunal Constitucional, núm. 15, 1999, pp. 15 y ss. Como sostiene este autor, la inadecuada aplicación del principio de proporcionalidad al legislador limitador de los derechos fundamentales realizada en la Sentencia acaba por convertir a los derechos fundamentales en un instrumento al servicio de la opinión pública libre como un valor ubicado por encima del texto constitucional de 1978 (cfr. pp. 39 y 40).

43. Contrariamente a lo que acontece en el art. 9.2 a) en el que promover, justificar o exculpar parece aludir a conductas expresivas, fomentar, propiciar o legitimar no sólo engloban conductas expresivas, sino también comportamientos que son objeto de otros derechos fundamentales como el derecho de asociación. Ese puede ser el caso de militantes del partido que colaboren con asociaciones que fomenten o promuevan el uso de la violencia. Ello se ve, por ejem- 
rentemente, el art. 9.2 b) lo que excluye de aquellos derechos no son objetivos políticos, sino la utilización de métodos violentos en su persecución. De tal manera, el art. 9.2 b) se presenta compatible con el principio de lealtad constitucional como instituto de defensa del Estado. El problema surge, no obstante, cuando el art. 9.3 LPP establece las actividades concretas con las que se puede verificar la existencia del supuesto de ilicitud contemplado en el art. 9.2 b). Así, por ejemplo, para el art. 9.3 d), debe considerarse fomentar, propiciar o legitimar la violencia como método para la consecución de objetivos políticos

Utilizar como instrumentos de la actividad del partido, conjuntamente con los propios o en sustitución de los mismos, símbolos, mensajes o elementos que representen o se identifiquen con el terrorismo o la violencia y con las conductas asociadas al mismo.

Pudiera parecer que para el art. 9.3 d) LPP lo capital es que los símbolos, mensajes o elementos representen o se identifiquen con determinadas actividades consideradas ilícitas: el terrorismo y la violencia, al margen de su contenido político o ideológico. De este modo, el art. 9.3 d) se habría alejado de los presupuestos de la defensa de la Constitución. No obstante, la técnica legislativa empleada acaba conduciendo a una ilicitud soterrada de los fines partidistas. El art. 9.3 d) exige, a simple vista, del aplicador de la ley examinar si los símbolos, mensajes y elementos empleados por los partidos se asocian a las actividades ilícitas expresadas en el art. $9.3 \mathrm{~d}$ ): el terrorismo o la violencia. Sin embargo, esta disposición exige del aplicador de la LPP que identifique el contenido ideológico del símbolo, mensaje o elemento con las actividades empleadas, de ordinario, en su persecución. El problema es que, realizada tal identificación, ya no resulta posible la distinción entre los fines partidistas y los medios utilizados en su persecución. Lo uno y lo otro no son sino la misma cosa. Por ello, si los medios utilizados por los partidos se encuadran en los supuestos de ilicitud del art. $9.2 \mathrm{~b}$ ) LPP -terrorismo, violencia o las conductas asociadas a los mismos- la antijuridicidad no se predica exclusivamente de ellos sino, como consecuencia de la identificación realizada, tácitamente de los fines mismos. Esta proyección de la ilicitud de los medios a los fines, a consecuencia del juicio previo de identificación, acaba impidiendo -en contradicción con la concepción procedimental de democracia- a las ideologías asociadas con el terrorismo y la violencia cualquier ámbito en el cual puedan desplegarse lícitamente ${ }^{44}$. Es decir, aquellas ideologías ni siquiera

plo, en el art. 9.3 c) LPP en el que se dispone que para verificar la concurrencia de los supuestos de ilicitud del art. $9.2 \mathrm{a}$, b y c, debe tenerse en cuenta, entre otras conductas, la doble militancia de los afiliados del partido en organizaciones o entidades vinculadas a un grupo terrorista o violento.

44. Una diferente consideración merece el cierre del Estadio Vicente Calderón por la exhibición de símbolos nazis acordado en base al art. 27.2 de la Ley 17/1997, de la Comunidad Autó- 
pudieran ser perseguidas al margen de actividades terroristas o violentas -exigencia del principio de lealtad como defensa del Estado-, y no porque fácticamente no pueda ser posible, sino porque el art. $9.2 \mathrm{~b}$ ) LPP articula una identificación o presunción que no admite prueba en contrario. Esta técnica de la identificación es por la que también ha optado el legislador penal en el art. 607.2. En el mismo se establece la ilicitud penal de la difusión por cualquier medio de ideas o doctrinas que ... pretendan la rebabilitación de regímenes $o$ instituciones que amparen prácticas generadoras de los mismos-supuestos de ilicitud del art. 607.1-45. De una forma todavía más evidente que el art. 9.3d), este tipo penal reconoce la ilicitud de los fines políticos cuando se identifiquen, de ordinario, con los medios reputados como delictivos por el art. 607.1 CP. La exigencia derivada de la concepción constitucional del principio democrático de conferir un ámbito de licitud para la expresión de fines políticos sólo puede ser conseguido si se renuncia a la técnica de la identificación y se opta por el examen de la ilicitud de las concretas manifestaciones realizadas.

9.2 c) Complementar y apoyar politicamente la acción de organizaciones terroristas para la consecución de sus fines de subvertir el orden constitucional o alterar gravemente la paz pública, tratando de someter a un clima de terror a los poderes públicos, a determinadas personas o grupos de la sociedad o a la población en general, o contribuir a multiplicar los efectos de la violencia terrorista y del miedo y la intimidación generada por la misma

noma de Madrid, de 4 de julio, de Espectáculos Públicos y Actividades Recreativas que dispone que podrá acordarse el cierre de los locales o establecimientos que cuenten con licencia cuando exista grave riesgo para la seguridad de las personas y bienes o para la salubridad pública. El mismo sentido adoptado por la medida administrativa de la Comunidad de Madrid se observa en el art. 66.1 de la Ley 10/1990, de 15 de octubre, del Deporte, en el que se dispone queda probibida la introducción y exhibición en espectáculos deportivos de pancartas, símbolos, emblemas o leyendas que impliquen una incitación a la violencia. Como se puede ver en ellas no se asume la técnica de la identificación del art. 9.3d) LPP. La redacción de la disposición ahora analizada exige del aplicador de la ley declarar la ilicitud sólo cuando la expresión de las ideologías inciten a la violencia.

45. Este precepto dispone que los que, con propósito de destruir total o parcialmente a un grupo nacional, étnico, racial o religioso, perpetraren alguno de los actos siguientes, serán castigados:

1. Con la pena de prisión de quince a veinte años, si mataran a alguno de sus miembros. Si concurrieran en el becho dos o más circunstancias agravantes, se impondrá la pena superior en grado.

2. Con la prisión de quince a veinte años, si agredieran sexualmente a alguno de sus miembros o produjeran alguna de las lesiones previstas en el artículo 149.

3. Con la prisión de ocho a quince años, si sometieran al grupo o a cualquiera de sus individuos a condiciones de existencia que pongan en peligro su vida o perturben gravemente su salud, o cuando les produjeran algunas de las lesiones previstas en el artículo 150.

4. Con la misma pena, si llevaran a cabo desplazamientos forzosos del grupo o sus miembros, adoptaran cualquier medida que tienda a impedir su género de vida o reproducción, o bien trasladaran por la fuerza individuos de un grupo a otro.

5. Con la de prisión de cuatro a ocho años, si produjeran cualquier otra lesión distinta de las señaladas en los números 2 y 3 de este apartado. 
El tercero y último supuesto de ilicitud de los partidos se refiere en el art. 9.2 c) LPP al apoyo o complementación de la acción de las organizaciones terroristas. El problema reside en precisar el significado que posee el concepto "complementación y el apoyo" de la acción terrorista. De conformidad con lo expuesto, tales conceptos no pueden identificarse, so pena de reiteración, con promover, justificar o exculpar atentados contra la vida o integridad de las personas (art. 9.2 a) ni con fomentar, propiciar, legitimar la violencia como método de consecución de objetivos políticos (art. 9.2 b). Lo que declara ilícito esta disposición no es una acción directa favorecedora de la actividad terrorista o violenta -ya que ello entraría dentro de los supuestos de ilicitud de los arts. 9.2 a y b) - sino el mero hecho de ofrecer un soporte político e ideológico a la acción de organizaciones terroristas para subvertir el orden constitucional. Tal cosa parece quedar clara en la concreción de las conductas que realiza el art. 9.3 LPP, cuyo punto tercero alude a dar apoyo expreso o tácito al terrorismo. La alusión al apoyo tácito -además del expreso que pudiera caer dentro de los supuestos de ilicitud de los arts. 9.2 a y b)- permite afirmar que la ilicitud del art. $9.2 \mathrm{c}$ ) se predica del mero soporte político o ideológico a una organización terrorista. Ello se percibe claramente en el art. 9.3 b) LPP en el que se pone de manifiesto uno de los elementos que debe ser tenido en cuenta para verificar la existencia del supuesto de ilicitud del art. 9.2 c). En aquél se declara ilícito

Acompañar la acción de la violencia con programas y actuaciones que fomentan una cultura de enfrentamiento y confrontación civil ligada a la actividad de los terroristas, o que persiguen intimidar, hacer desistir, neutralizar o aislar socialmente a quienes se oponen a la misma, haciéndoles vivir cotidianamente en un ambiente de coacción, miedo, exclusión o privación básica de las libertades $y$, en particular, de la libertad para opinar y para participar libre y democráticamente en los asuntos públicos.

Como se puede percibir, la ilicitud se vincula al mero acompañamiento de la acción de la violencia con programas que fomenten una cultura de enfrentamiento y confrontación civil. En realidad, la LPP convierte en ilícitos aquellos partidos por su mera coincidencia ideológica con los fines de subvertir el orden constitucional propios de una organización terrorista, llegándose así a un resultado favorable a la defensa de la Constitución. Sin embargo, si ello es así, parece difícil poder justificar la expresa alusión en el art. 9.3 c) a la acción de organizaciones terroristas. Ello se explica por la aparente intención de renunciar en la LPP a ilegalizar expresamente ideologías políticas, pero sí hacerlo de manera tácita. La alusión a la acción de las organizaciones terroristas se explica por el empleo, al igual que en el art. 9.2 b), de la técnica de la identificación entre fines y medios. En realidad, lo que viene a hacer el art, $9.2 \mathrm{c}$ ) es presumir que la coincidencia de fines políticos entre un partido político y una organización terrorista hace partícipe a aquél de la acción ilícita de ésta. De cualquier modo, el dato más convincente que permite afirmar la pretensión del art. 9.2 c) de 
articular un principio de lealtad como instituto de defensa de la Constitución es el art. 9.3 c) LPP que dispone que debe tenerse en cuenta para afirmar el supuesto de ilicitud del art. $9.2 \mathrm{c}$ )

Incluir regularmente en sus órganos directivos o en sus listas electorales personas condenadas por delitos de terrorismo que no hayan rechazado püblicamente los fines y los medios terroristas, o mantener un amplio número de sus afiliados doble militancia en organizaciones o entidades vinculadas a un gripo terrorista o violento, salvo que hayan adoptado medidas disciplinarias contra éstos conducentes a su expulsión.

Esta disposición constituye otro argumento capital para intentar demostrar que el art. 9.2 c) LPP conduce a declarar ilícita la mera coincidencia ideológica con los fines de una organización terrorista y que irradia al partido la ilicitud de los medios utilizados por ésta. La obligación que pesa sobre los militantes del partido de rechazar los fines de la organización terrorista y, en caso de negativa, el deber del partido de expulsarles sólo puede comprenderse si, tal como acontece, el art. 9.2 c) declara ilícitos aquellos partidos políticos que, sólo por sus fines, coincidan con los propios de una organización terrorista.

En definitiva, la LPP acaba articulando un principio de lealtad constitucional como un instituto de defensa de la Constitución. Sin embargo, tal cosa no se realiza de forma directa sino mediante dos métodos que acaban conduciendo, de manera subrepticia, a la ilegalización de ideologías partidistas. El primero de ellos, el consagrado en el art. 9.2 a), consiste en la deliberada amplitud del supuesto de hecho de ilicitud que permite que, junto a actividades que deben considerarse ilícitas, puedan llegar a encuadrarse otras que constituyen una legítima persecución de ideologías contrarias a la CE. El segundo de los métodos empleados en los arts. $9.2 \mathrm{~b}$ y c) LPP para llegar a la defensa de la Constitución consiste en el empleo de la técnica de la identificación mediante la cual se imputa, sin admitir prueba en contrario -en ello reside su problema de constitucionalidad-, a determinadas ideologías la adopción de determinados medios que se consideran antijurídicos. De este modo, sobre la base de la ilicitud de tales medios, se llega a la ilicitud de la ideología misma. La posibilidad de que, sobre la base de una sentencia interpretativa del TC, pueda soslayarse la configuración del principio de lealtad constitucional de la LPP como instituto de defensa de la Constitución pudiera aceptarse en el caso de los enunciados en los que se establecen los supuestos generales de ilicitud, esto es, en los arts. 9.2 a, b y c) LPP. Sin embargo, la determinación en el art. 9.3 LPP de las conductas que deben ser tenidas en cuenta para verificar la existencia de tales supuestos de ilicitud del art. $9.2 \mathrm{a}$, b y c LPP, hacen difícil sortear la inconstitucionalidad de la LPP. El art. 9.3 LPP acaba conduciendo, de forma inevitable, a la ilicitud de la persecución de ideologías contrarias a la CE. 


\section{EL CONTENIDO DEL PRINCIPIO DE LEALTAD CONSTITUCIONAL FRENTE A LOS PARTIDOS POLÍTICOS}

Examinada la concepción constitucionalmente adecuada de la lealtad constitucional y la consagrada en la LPP -y al margen de que ésta, como ha quedado dicho, se distancie de aquélla- se analizará a continuación cuál es el contenido que la $\mathrm{CE}$ ha pretendido conferir al principio de lealtad.

\section{a) EL PRINCIPIO DE LEALTAD CONSTITUCIONAL HACIA ABAJO}

El primero de los modos posibles de determinar el contenido del principio de lealtad constitucional frente a los partidos políticos del art. $6 \mathrm{CE}$ puede realizarse con arreglo a la distinción entre la lealtad constitucional hacia arriba y hacia abajo. Este dualismo expresa respectivamente la proyección de la eficacia de los principios estructurales frente al poder público y frente a los particulares ${ }^{46}$. En lo que se refiere al contenido del principio de lealtad del art. $6 \mathrm{CE}$, la concepción de los partidos políticos como entidades de naturaleza privada -aun con funciones jurídico-públicas $-{ }^{47}$ conduce a atribuir a aquel principio un contenido hacia abajo.

\section{b) EL CONTENIDO REPRESIVO Y PREVENTIVO DEL PRINCIPIO DE LEALTAD CONSTITUCIONAL}

Otra de las clasificaciones que aluden al contenido del principio de lealtad es la que distingue entre un carácter represivo y preventivo. El contenido represivo del principio de lealtad constitucional implica negar amparo normativo a las actividades que supongan un menoscabo de la eficacia de los principios fundamentales de la Constitución. Lo capital aquí es que las consecuencias jurídicas del principio de lealtad constitucional se activan una vez que la lesión ha tenido lugar. En ese sentido la función de la lealtad constitucional consiste precisamente en reprimir. Por el contrario, el principio de lealtad constitucional adquiere un carácter preventivo si el mismo priva de cobertura normativa a actividades que puedan llegar constituir un menoscabo de la eficacia de los principios estructurales. De tal manera, se pretende que su lesión ni siquiera pueda llegar a producirse $^{48}$. El contenido represivo o preventivo del principio de lealtad constitu-

46. Cfr. U. SCHEUNER, "Der Verfassungsschutz im Bonner Grundgesetz" en VV.AA. Um Recht. und Gerechtigkeit. Festgabe für Erich Kaufmann, ed. Kohlhamer, Stuttgart, y Colonia 1950, pp. 321 y ss.

47. Véase la STC $10 / 1983$, de 21 de febrero, FJ $3 .^{\circ}$ y la $23 / 1983$, de 20 de febrero, FJ $4 .^{\circ}$. En la doctrina R. L. Blanco Valdés, Los partidos políticos, op. cit., pp. 141 y ss.

48. Cfr. U. SCHEUNER, "Der Verfassungsschutz im Bonner Grundgesetz", op. cit., pp. 325 y 326; K. Hesse, Grundzüge des Verfassungsrechts der Bundesrepublik Deutschland, ed. CF. Müller, Heidelberg, 1990, 273. 
cional no cabe deducirlo del texto del art. $6 \mathrm{CE}$ cuya cláusula funcionamiento democrático se limita simplemente a negar amparo normativo a actividades contrarias a la eficacia del principio democrático. Si esta eficacia se pone en peligro por la existencia de una lesión o por la mera posibilidad de que tal cosa pueda llegar a producirse es algo que no puede deducirse del propio art. $6 \mathrm{CE}$ sino de su desarrollo legislativo. De este modo, el análisis del contenido del principio del art: 6 CE debe realizarse sobre la base de la regulación contenida en la LPP, en particular, en los particulares supuestos de ilicitud contemplados en el art. 9.2 a, b y c).

El examen del primero de ellos, el art. 9.2 a), no debe practicarse de forma exclusiva con arreglo a la fórmula promover, justificar o exculpar los atentados contra la vida o la integridad de las personas. Lo capital para determinar el contenido del principio de lealtad constitucional es la vulneración sistemática de libertades y derechos fundamentales erigida en presupuesto. Precisamente porque se trata de una vulneración, para el art.9.2 a) lo capital es que se produzca una lesión de normas constitucionales, que es la que se declara ilícita. En ese sentido el art.9:2 a) confiere al principio de lealtad un contenido represivo. No obstante, la vulneración sistemática de derechos fundamentales del art. 9.2 a) se encuentra ausente en los supuestos de ilicitud de los arts. 9.2 b y c). En el segundo de ellos, el art. 9.2 b), se postula la ilicitud de actividades que tiendan a fomentar, propiciar o legitimar la violencia. En este caso, no se trata, como en los delitos de apología del $\mathrm{CP}$, de una actividad que constituye una incitación directa a cometer un delito. Parece claro que fomentar, propiciar o legitimar la violencia no presupone una lesión directa de los derechos fundamentales frente a cuya infracción tutela la legislación penal en los delitos de apología. Ello es lo que permite explicar la existencia de unos supuestos de ilicitud como los contemplados en el art. 9 LPP que, si coincidiesen con la regulación penal, carecerían de todo sentido. En realidad, la finalidad del supuesto del art. 9.2 b) es permitir declarar ilegal un partido cuyas actividades puedan llegar a legitimar la violencia. Esta ausencia de una vinculación directa entre la actividad partidista y los derechos fundamentales tutelados en el art. 9.2 b) acaban atribuyendo al principio de lealtad constitucional un contenido preventivo. La vulneración sistemática de libertades tampoco aparece en el supuesto de ilicitud contemplado en el art. 9.2 c). Sin embargo, ello no significa que esta disposición no identifique eficacia y lesión. Como ha quedado dicho anteriormente, el art. 9.2 c) viene a sancionar -conforme a presupuestos de defensa de la Constitución- la coincidencia de los fines del partido con los de una organización terrorista. Sin embargo, ello se realiza, como se ha analizado, sobre la base de la imputación a los fines del partido, de los medios ilícitos adoptados por una organización terrorista. Al margen de que ello rèsulte incompatible con la concepción constitucionalmente adecuada del principio de lealtad, lo capital en este punto es comprobar que se imputan a los partidos actividades terroristas que constituyen una lesión efectiva de derechos fundamentales. Por ello el art. 9.2 c) LPP confiere al principio de lealtad constitucional un contenido represivo, al igual que el art. 9.2 a). 


\section{C) El CONTENIDO PASIVO DEL PRINCIPIO DE LEALTAD CONSTITUCIONAL}

Una última clasificación del contenido del principio de lealtad constitucional es la que distingue entre su posible contenido activo y pasivo. El contenido activo del principio de lealtad constitucional supone erigir a los principios estructurales en objeto de la actividad de los sometidos a la Constitución. En ese sentido, el principio de lealtad exigiría un comportamiento favorable a la eficacia de su objeto. Por el contrario, el contenido pasivo del principio de lealtad constitucional implica presentar a los principios estructurales como un límite al comportamiento de los destinatarios de la Constitución. Con arreglo a estas premisas, la eficacia de su objeto exige una mera abstención ${ }^{49}$. El contenido activo o pasivo del principio de lealtad en la CE de 1978 debe determinarse con arreglo a la diferente vinculación que poderes públicos y particulares poseen al ordenamiento jurídico. Como ha puesto de manifiesto la STC 101/1983, de 18 de noviembre,

La sujeción a la Constitución es una consecuencia obligada de su carácter de norma suprema, que se traduce en un deber de distinto signo para los ciudadanos y los poderes públicos; mientras los primeros tienen un deber general negativo de abstenerse de cualquier actuación que vulnere la Constitución, sin perjuicio de los supuestos en que la misma establece deberes positivos (arts. 30 y 31, entre otros), los titulares de los poderes públicos tienen además un deber general positivo de realizar sus funciones de acuerdo con la Constitución (FJ. 3. ${ }^{\circ}$.

Por ello, los particulares, y también los partidos políticos, como asociaciones de naturaleza privada, tienen un deber general de abstenerse de actuaciones vulneradoras de la Constitución. De tal manera, se desprende que las normas de la Constitución y, consecuentemente, la particular vinculación realizada por la lealtad constitucional a las que consagran los principios estructurales, se presentan como un límite a la actividad de los partidos. Esto se ve en la regulación de los supuestos de ilicitud por vulneración del principio democrático realizada por la LPP. Promover, justificar o exculpar atentados contra la vida o la integridad de las personas -art. $9.2 \mathrm{a}-$, fomentar, propiciar o legitimar la violencia -art. 9.2 b-, y complementar y apoyar la acción de las organizaciones terroristas -art. $9.2 \mathrm{c}$ - constituyen normas que gozan de una estructura de prohibición y no de mandato como hubiese requerido el contenido activo del principio de lealtad constitucional. La omisión se presenta para la LPP como una actividad lícita. El único supuesto en el que no ocurre esto es el de la conducta concretada en el art. 9. 3 c). Esta disposición acaba atribuyendo un contenido activo al principio de lealtad puesto que la exigencia respecto de los militantes de rechazar los fines y los medios terroristas y, en caso de negativa, la obligación del partido de adoptar medidas conducentes a su expresión erige al principio democrático en objeto de su actividad.

49. Cfr. J. LAMEYER, Streitbare Demokratie, op. cit., p. 41; J. BECKER, "Die Webrhafte Demokratie des Grundgesetzes", op. cit., p. 335. 